\title{
The Impact of Climate Change on Heart Failure: A Narrative Review Study
}

\author{
Sasha Kakaei (iD) ${ }^{1}$, Masoumeh Zakerimoghadam (iD ${ }^{2}$, Mehrzad Rahmanian ${ }^{3}$ and Zahra Abbasi \\ Dolatabadi ${ }^{1, *}$ \\ ${ }^{1}$ Department of Critical Care Nursing, School of Nursing and Midwifery, Tehran University of Medical Sciences, Tehran, Iran \\ ${ }^{2}$ Department of Medical-Surgical Care Nursing, School of Nursing and Midwifery Tehran University of Medical Sciences, Tehran, Iran \\ ${ }^{3}$ Department of Cardio Vascular Surgical, Complex of Imam Hospital, Tehran University of Medical Sciences, Tehran, Iran \\ "Corresponding author: Department of Critical Care Nursing, School of Nursing and Midwifery, Tehran University of Medical Sciences, Tehran, Iran. Email: \\ zahra_abasi2000@yahoo.com
}

Received 2020 July 26; Revised 2021 January 18; Accepted 2021 January 24

\begin{abstract}
Context: Climate change as a global threat has affected all aspects of society, including health. This study aimed to identify the role of climate change factors on cardiovascular diseases.

Evidence Acquisition: The current narrative review study searched the databases including EMBASE, PubMed, Science Direct, Ovid, Cochrane Library, Magiran, and SID using Persian and English keywords such as 'climate change', 'cold wave', 'heat wave', 'temperature decrease', 'temperature rise', 'heart disease', 'heart attack', and 'heart failure' from the beginning of 2000 to the end of 2019. Results: Previous studies have shown that physical factors affect health and contribute to conditions such as cardiovascular disease and even death. Additionally, a relationship can be found between temperature decrease and heart diseases in the literature, while recent studies have shown that temperature rise is directly related to heart diseases.

Conclusions: Due to increased greenhouse gas emissions and the increase in temperature, the world is witnessing a massive climate change. Considering the increase in the incidence and mortality rates due to heart diseases and the role of climate change in this increase, health policymakers need to focus on setting guidelines for reducing the complications of these diseases in high-risk groups based on the relevant studies.
\end{abstract}

Keywords: Climate Change, Cardiovascular Disease, Heart Failure, Global Warming, Disasters

\section{Context}

Climate change refers to any lasting change in the Earth's climate over a period of time $(1,2)$. Global warming is a type of climate change in which the average temperature in the lower layers of the Earth's atmosphere is increased due to factors such as greenhouse gas emissions and air pollution (3-6). Estimates indicate that the annual average temperature and frequency of the heat wave are increasing. Climate change and increased global warming, in addition to economic and social impacts, have become a potential threat to human health (1, 7-11). According to a report by the center for research on the epidemiology of disasters (CRED), $44 \%$ of the 147 events recorded in the first quarter of 2017 were due to climate change. Environmental and climate changes have direct and indirect effects on health, human well-being, and the mortality pattern of infectious and noncommunicable diseases (NCDs) (12-15).

Climate change has caused an increasing number of people with health problems, such as the elderly, children, and patients, to be at risk (16-19). Climate change has contributed to death due to heat-stroke, non-infectious diseases such as cardiovascular, pulmonary, malnutrition, and contagious diseases $(4,11,20,21)$. However, the slowing down of cold winters, hence fewer cold season illnesses such as respiratory diseases, and the increase in agricultural production are among the positive effects of climate change (22). On the other hand, the increase in air temperature during the recent years has predisposed some patients with non-respiratory diseases such as cardiovascular disease to temperature change complications more than other people in the community $(23,24)$. Various studies have reported a correlation between air temperature changes (decrease or increase) and compromising heart health $(11,14,17,19,21,25-27)$.

For example, in patients with heart failure, the increase in temperature increases the incidence of disabling complications $(25,28)$. To achieve full health in these individ- 
uals, at least some basic needs must be provided; needs that are undergoing changes as a result of climate change. Among these changes is a reduction in healthy and adequate food and water resources in societies. On the other hand, following the increase in sweating in the rising temperature, the chance of drug poisoning increases and can be a factor of referral and re-admitting individuals to treatment centers $(23,29,30)$. The World Health Organization (WHO) has declared climate change and NCDs, including cardiovascular disease, in 2019 as two main health threats $(11,17)$. Despite all the scientific advances in the prevention and treatment of diseases, cardiovascular disease is still considered the first cause of death worldwide (31-33). Prevention of these diseases, as well as the reduction of complications, disability, and death in various age and sex groups, are among the most important goals of the health system in the world (34). Considering the widespread occurrence of cardiovascular diseases, conducting a comprehensive study on the factors affecting the patients and those who are predisposed to these diseases is an important issue in reducing their tangible and intangible complications. Therefore, this study aimed to identify the role of climate change factors on cardiovascular diseases.

\section{Evidence Acquisition}

The current narrative review study searched the databases including EMBASE, PubMed, Science Direct, Ovid, Cochrane Library, Magiran, and SID using Persian and English keywords such as 'climate change', 'cold wave', 'heat wave', 'temperature decrease', 'temperature rise', 'heart disease', 'heart attack', and 'heart failure' from the beginning of 2000 to the end of 2019. A total of 150 articles were retrieved from these databases, and their abstracts were evaluated by the research team. According to the availability of full-text of the articles and their relationship with the subject of the study, 50 papers were finally included in the study (Figure 1).

\section{Results}

Climate change affects the heart health through air pollution, increase in air temperature, and dietary changes (35). Following the increase in air temperature, the contractility of the heart decreases. On the other hand, temperature increase leads to an increase in the central body temperature, which in turn causes the body's compensating mechanism to increase the heart rate and direct blood flow to the skin through central organs, such as the heart and kidneys. The body increases sweating to adjust its temperature. In a patient with heart disease, the heart's re- duced ability to circulate blood to vital organs can contribute to worsening of the symptoms and threatening the life of the individual $(16,34,36)$. Studies from around the world have shown that climate change has increased the deaths of people with heart disease (37).

Cardiac attacks, as one of the most common cardiac disorders, account for more than one third of deaths in developing countries $(10,38)$. Studies have shown that cardiovascular disease is a result of environmental stressors, including air temperature; moreover, there is a relationship between the heart disease morbidity and mortality rates and the highest and lowest temperatures (20, 39-41). According to various studies, the association between the reduction of air temperature and the increase in the incidence and mortality from heart disease in different age groups has been confirmed, and cold weather is known as one of the most important environmental stressors in cardiac patients $(39,42,43)$. However, in recent years, consistent with global warming and temperature increase across the world, several studies have been conducted to investigate the effect of this temperature change on the pattern of NCDs, including cardiovascular disease, whose findings have been contradictory $(5,9,44)$.

The results of a study on the effect of rising air temperature on the death rate in a wave of heat in Adelaide, Australia, in 2009 showed that, unfortunately, mortality rates and hospitalization of people with chronic illnesses increased following a rise in air temperatures (40). Research conducted in Europe has shown that for every onedegree temperature increase, the mortality rate from cardiovascular diseases in the southern and northern regions increases by 3.12 and $1.84 \%$, respectively (16). The results of a study conducted in Michigan showed that as a result of an increase in the air temperature, the rate of heart attack increases with changes in the ST segment in the electrocardiogram (1). In a study conducted in Beijing between 2000 and 2011, the results showed that with the increase in air temperature, mortality from heart diseases increased and needed to be addressed by health policy-makers (39). In another study in the Catalonia region of Spain during 2006 2013 , it was found that the hospitalization rate of patients due to cardiovascular diseases increases as a result of a decrease in the air temperature (20). According to the results of a research in Japan, lower air temperatures contribute to a rise in the mortality rate from heart diseases $(3,45)$. In line with the Japanese findings, a study in England showed that death from heart diseases in people over 60 years old increased due to lower air temperatures $(42,43)$.

In recent studies in Iran, contradictory results have been reported. In some studies, findings have shown that deaths from cardiovascular diseases, pulmonary diseases and traumas have increased as a result of higher air tem- 


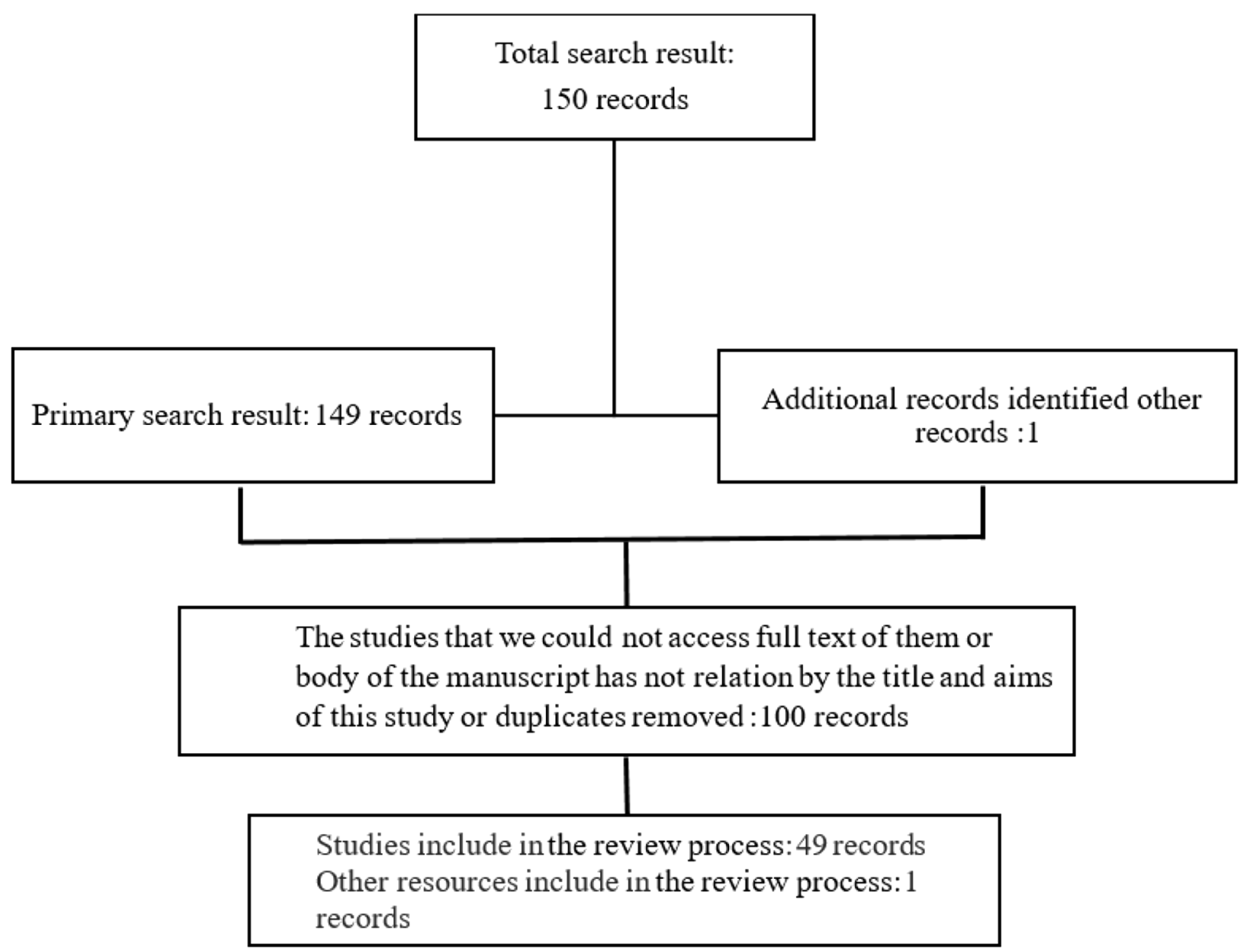

Figure 1. PRISMA diagram

peratures $(4,7,29,35,36,46,47)$. In a study conducted in Mashhad between 2004 and 2013, there was a direct correlation between the increase in air temperature and death from cardiovascular diseases. The study predicted that a rise in temperature in that city during the next decade would result in a $4.27 \%$ increase in deaths from cardiovascular diseases (4). However, in another study conducted in Shiraz from 2006 to 2012, there was no significant relationship between temperature changes and death from heart diseases (26).

The findings of most studies in Iran have shown that increased mortality from cardiovascular diseases is associated with lower air temperatures. The results of a study conducted in Kerman over a four-year period showed that there is a negative relationship between air temperature changes and death from heart diseases, i.e. an increase in death due to heart disease followed by a decrease in air temperature (35). The results of the study conducted by Farajzadeh and Darand during 2000 - 2005 in Tehran showed that with decreasing air temperature, the death rate due to heart diseases increased (31). Furthermore, the results of a study carried out by Fallah Ghalhari and Mayvaneh in Mashhad on the effect of air temperature on deaths from pulmonary diseases in a period of 10 years from 2004 to 2013 showed a negative and an inverse relationship (29). Several studies have been conducted over recent years on the effect of air temperature as an important environmental stressor on the pattern and burden of cardiovascular diseases (48-50). Finally, the results obtained in these studies vary in different parts of the world.

\section{Conclusions}

Considering the increasing climate change and global warming, recognizing climate change and its effects on human health is an important issue for the stake-holders. 
Heart diseases have a range of symptoms and disorders that affect different age, sex, and occupation groups. With regard to the impact of climate change and the increase in air temperature on the health of people, especially those with heart disease, various studies with contradictory results have been conducted worldwide. The results of some of these studies have shown a positive and direct effect of increasing air temperature on cardiovascular health complications, while some studies have considered this effect insignificant. Considering the world's most up-to-date policies for controlling the effects of greenhouse gas emissions, global warming, and climate change, it is necessary to pay more attention to the health of the population, especially cardiovascular health. Also, it is essential that further research be conducted on the effects of temperature changes on the health of the heart and, based on the results, mega planning and designing related guidelines be carried out by health policy-makers to prevent and reduce the complications of heart disease in at-risk groups.

\section{Acknowledgments}

This study is part of a student thesis to obtain a master's degree in nursing registered in Tehran University of Medical Sciences, Iran, in 2020 (ethics code: IR.TUMS.FNM.REC.1399.057). The authors would like to thank the people who participated in this study.

\section{Footnotes}

Authors' Contribution: All authors contributed to designing, running, and writing all parts of the research.

Conflict of Interests: The authors declare that there is no conflict of interest regarding the publication of this paper.

Ethical Approval: This study is part of a student thesis to obtain a masters degree in nursing which has been registered in Tehran University of Medical Sciences in 2020 with ethics code IR.TUMS.FNM.REC.1399.057.

Funding/Support: This research did not receive any specific grant from funding agencies in the public, commercial, or not-for-profit sectors.

\section{References}

1. Andersson HB, Seth M, SlyJ, Bates E, Gurm H. Daily temperature fluctuations and myocardial infarction: Implications of global warming on cardiac health. J Am Coll Cardiol. 2018;71(11). A1152. doi: 10.1016/s07351097(18)31693-0.

2. Deputy Minister of Human Environment. [National strategic plan on climate change]. Tehran, Iran: Department of Environment; 2017. Persian.
3. Atsumi A, Ueda K, Irie F, Sairenchi T, Iimura K, Watanabe H, et al. Relationship between cold temperature and cardiovascular mortality, with assessment of effect modification by individual characteristics: Ibaraki Prefectural Health Study. Circ J. 2013;77(7):1854-61. doi: 10.1253/circj.cj-12-0916. [PubMed: 23595035].

4. Baaghideh M, Mayvaneh F. Climate change and simulation of cardiovascular disease mortality: A case study of Mashhad, Iran. Iran J Public Health. 2017;46(3):396-407. [PubMed: 28435826]. [PubMed Central: PMC5395536].

5. Wei M, Qiao F, Deng J. A quantitative definition of global warming hiatus and 50-year prediction of global-mean surface temperature. J Atmos Sci. 2015;72(8):3281-9. doi: 10.1175/jas-d-14-0296.1.

6. World Health Organization. Climate and health country profiles 2015: A global overview. Geneva, Switzerland: World Health Organization; 2015.

7. Bhatnagar A. Environmental determinants of cardiovascular disease. Circ Res. 2017;121(2):162-80. doi: 10.1161/CIRCRESAHA.117.306458. [PubMed: 28684622]. [PubMed Central: PMC5777598].

8. Benjamin EJ, Blaha MJ, Chiuve SE, Cushman M, Das SR, Deo R, et al. Heart disease and stroke statistics-2017 update: A report from the American Heart Association. Circulation. 2017;135(10):e146-603. doi: 10.1161/CIR.0000000000000485. [PubMed: 28122885]. [PubMed Central: PMC5408160].

9. Umair Shahzad R. Global warming: Causes, effects and solutions. Durreesamin. 2015;1(4).

10. Pagidipati NJ, Gaziano TA. Estimating deaths from cardiovascular disease: A review of global methodologies of mortality measurement. Circulation. 2013;127(6):749-56. doi: 10.1161/CIRCULATIONAHA.112.128413. [PubMed: 23401116]. [PubMed Central: PMC3712514].

11. World Health Organization. Ten threats to global health in 2019. Geneva, Switzerland: World Health Organization; 2021, [cited 2019 Jan 27th]. Available from: https://www.who.int/news-room/spotlight/ ten-threats-to-global-health-in-2019.

12. Centre for Research on the Epidemiology of Disasters. Cred crunch: Disaster data: A balanced perspective. CRED. 2017;(48).

13. Hayashida K, Shimizu K, Yokota H. Severe heatwave in Japan. Acute Med Surg. 2019;6(2):206-7. doi:10.1002/ams2.387. [PubMed:30976451]. [PubMed Central: PMC6442519].

14. Martinez GS, Imai C, Masumo K. Local heat stroke prevention plans in Japan: Characteristics and elements for public health adaptation to climate change. Int J Environ Res Public Health. 2011;8(12):4563-81. doi: 10.3390/ijerph8124563. [PubMed: 22408589]. [PubMed Central: PMC3290973].

15. Frumkin H, Hess J, Luber G, Malilay J, McGeehin M. Climate change: The public health response. Am J Public Health. 2008;98(3):435-45. doi: 10.2105/AJPH.2007.119362. [PubMed: 18235058]. [PubMed Central: PMC2253589].

16. Wichmann J, Andersen ZJ, Ketzel M, Ellermann T, Loft S. Apparent temperature and cause-specific mortality in Copenhagen, Denmark: A case-crossover analysis. Int J Environ Res Public Health. 2011;8(9):371227. doi: 10.3390/ijerph8093712. [PubMed: 22016711]. [PubMed Central: PMC3194112].

17. World Health Organization. The top 10 causes of death. Geneva, Switzerland: World Health Organization; 2020, [updated 2020 Dec 9th; cited 2019 Jan 4th]. Available from: https://www.who.int/news-room/factsheets/detail/the-top-10-causes-of-death.

18. Kenny GP, Yardley J, Brown C, Sigal RJ, Jay O. Heat stress in older individuals and patients with common chronic diseases. CMAJ. 2010;182(10):1053-60. doi: 10.1503/cmaj.081050. [PubMed: 19703915]. [PubMed Central: PMC2900329].

19. Kenney WL, Craighead DH, Alexander LM. Heat waves, aging, and human cardiovascular health. Med Sci Sports Exerc. 2014;46(10):18919. doi: 10.1249/MSS.0000000000000325. [PubMed: 24598696]. [PubMed Central: PMC4155032]. 
20. Ponjoan A, Blanch J, Alves-Cabratosa L, Marti-Lluch R, Comas-Cufi $\mathrm{M}$, Parramon D, et al. Effects of extreme temperatures on cardiovascular emergency hospitalizations in a Mediterranean region: A self-controlled case series study. Environ Health. 2017;16(1):32. doi: 10.1186/s12940-017-0238-0. [PubMed: 28376798]. [PubMed Central: PMC5379535].

21. World Health Organization. Climate change and health. Geneva, Switzerland: World Health Organization; 2018, [updated 2018 Feb 1st; cited 2019 Jan 4th]. Available from: https://www.who.int/newsroom/fact-sheets/detail/climate-change-and-health\#: :text=Key\% 20facts, malaria\%2C\%20diarrhoea\%20and\%20heat\%20stress..

22. Rosegrant MW, Ewing M, Yohe G, Burton I, Saleemul H, ValmonteSantos R. Climate change and agriculture: Threats and opportunities. Germany: Verlag Nicht Ermittelbar; 2008.

23. De Blois J, Kjellstrom T, Agewall S, Ezekowitz JA, Armstrong PW, Atar D. The effects of climate change on cardiac health. Cardiology. 2015;131(4):209-17. doi: 10.1159/000398787. [PubMed: 25997478].

24. Blashki G, Armstrong G, Berry HL, Weaver HJ, Hanna EG, Bi P, et al. Preparing health services for climate change in Australia. Asia Pac J Public Health. 2011;23(2 Suppl):133S-43. doi: 10.1177/1010539510395121. [PubMed: 21447548].

25. Cui J, Sinoway LI. Cardiovascular responses to heat stress in chronic heart failure. Curr Heart Fail Rep. 2014;11(2):139-45. doi: 10.1007/s11897014-0191-y. [PubMed: 24599558]. [PubMed Central: PMC4042428].

26. Dadbakhsh M, Khanjani N, Bahrampour A. The relation between mortality from cardiovascular diseases and temperature in Shiraz, Iran, 2006-2012. ARYA Atheroscler. 2018;14(4):149-56. doi: 10.22122/arya.v14i4.1341. [PubMed: 30627190]. [PubMed Central: PMC6312568].

27. World Health Organization. Cardiovascular diseases (CVDs). Geneva, Switzerland: World Health Organization; 2017, [updated 2017 May 17th; cited 2019 Jan 4th]. Available from: https://www.who.int/newsroom/fact-sheets/detail/cardiovascular-diseases-(cvds).

28. Cui J, Arbab-Zadeh A, Prasad A, Durand S, Levine BD, Crandall CG. Effects of heat stress on thermoregulatory responses in congestive heart failure patients. Circulation. 2005;112(15):2286-92. doi: 10.1161/CIRCULATIONAHA.105.540773. [PubMed: 16216975].

29. Fallah Ghalhari G, Mayvaneh F. Effect of air temperature and universal thermal climate index on respiratory diseases mortality in Mashhad, Iran. Arch Iran Med. 2016;19(9):618-24. [PubMed: 27631176].

30. ANA Center for Ethics and Human Rights. Nurses' roles and responsibilities in providing care and support at the end of life. Maryland, USA: American Nurses Association; 2016.

31. Farajzadeh M, Darand M. [Analysis of air temperature influence on mortality in Tehran]. Hakim Res J. 2008;11(3):27-34. Persian.

32. Franchini M, Mannucci PM. Impact on human health of climate changes. Eur JIntern Med.2015;26(1):1-5. doi:10.1016/j.ejim.2014.12.008. [PubMed: 25582074].

33. Friel S, Bowen K, Campbell-Lendrum D, Frumkin H, McMichael AJ, Rasanathan K. Climate change, noncommunicable diseases, and development: the relationships and common policy opportunities. Annu Rev Public Health. 2011;32:133-47. doi: 10.1146/annurevpublhealth-071910-140612. [PubMed: 21091194].

34. Grasso M, Manera M, Chiabai A, Markandya A. The health effects of climate change: A survey of recent quantitative research. Int JEnviron Res Public Health. 2012;9(5):1523-47. doi: 10.3390/ijerph9051523. [PubMed: 22754455]. [PubMed Central: PMC3386570].

35. Khanjani N, Bahrampour A. Temperature and cardiovascular and respiratory mortality in desert climate. A case study of Kerman, Iran. Ira- nian J Environ Health Sci Eng. 2013;10(1):11. doi: 10.1186/1735-2746-10-11. [PubMed: 23369284]. [PubMed Central: PMC3570472].

36. Khanjani N. The effects of climate change on human health in Iran. Public Health Rev Int J Public Health. 2016;3(1):38-41. doi: 10.17511/ijphr.2016.i1.08.

37. Phung D, Guo Y, Thai P, Rutherford S, Wang X, Nguyen M, et al. The effects of high temperature on cardiovascular admissions in the most populous tropical city in Vietnam. Environ Pollut. 2016;208(Pt A):33-9. doi: 10.1016/j.envpol.2015.06.004. [PubMed: 26092390].

38. Ghanizadeh G, Heidari M, Seifi B, Jafari H, Pakjouei S. The effect of climate change on cardiopulmonary disease - A systematic review. J Clin Diagn Res. 2017;11(12):IE01-4. doi: 10.7860/jcdr/2017/26478.11012.

39. Tian Z, Li S, Zhang J, Guo Y. The characteristic of heat wave effects on coronary heart disease mortality in Beijing, China: A time series study. PLoS One. 2013;8(9). e77321. doi: 10.1371/journal.pone.0077321. [PubMed: 24098818]. [PubMed Central: PMC3786924].

40. Zhang Y, Nitschke M, Krackowizer A, Dear K, Pisaniello D, Weinstein P, et al. Risk factors for deaths during the 2009 heat wave in Adelaide, Australia: A matched case-control study. Int J Biometeorol. 2017;61(1):35-47. doi: 10.1007/s00484-016-1189-9. [PubMed: 27221967].

41. Hajat S, Kovats RS, Lachowycz K. Heat-related and cold-related deaths in England and Wales: Who is at risk? Occup Environ Med. 2007;64(2):93-100. doi: 10.1136/oem.2006.029017. [PubMed: 16990293]. [PubMed Central: PMC2078436].

42. Reed GW, Rossi JE, Cannon CP. Acute myocardial infarction. Lancet. 2017;389(10065):197-210. doi:10.1016/s0140-6736(16)30677-8.

43. Sartini C, Barry SJ, Whincup PH, Wannamethee SG, Lowe GD, Jefferis BJ, et al. Relationship between outdoor temperature and cardiovascular disease risk factors in older people. Eur J Prev Cardiol. 2017;24(4):34956. doi: 10.1177/2047487316682119. [PubMed: 27899528]. [PubMed Central: PMC5301906].

44. Huang J, Wang L, Wang S, Lu Y, Zhang W, Wang J. Spatial and temporal characteristics of temperature effects on cardiovascular disease in Southern China using the empirical mode decomposition method. Sci Rep. 2018;8(1):14775. doi: 10.1038/s41598-018-33184-6. [PubMed: 30283072]. [PubMed Central: PMC6170419].

45. Ng CF, Ueda K, Takeuchi A, Nitta H, Konishi S, Bagrowicz R, et al. Sociogeographic variation in the effects of heat and cold on daily mortality in Japan. J Epidemiol. 2014;24(1):15-24. doi: 10.2188/jea.je20130051. [PubMed: 24317342]. [PubMed Central: PMC3872520].

46. Sarrafzadegan N, Mohammmadifard N. Cardiovascular disease in Iran in the last 40 years: Prevalence, mortality, morbidity, challenges and strategies for cardiovascular prevention. Arch Iran Med. 2019;22(4):204-10. [PubMed: 31126179].

47. Hassanlouei B, Rezaeian M, Sheikh-Fathollahi M, Vazirinejad R. Impact of diurnal temperature variations on hospitalization due to cardiovascular and respiratory diseases in Rafsanjan, Iran, in 2008-2013. JOHE. 2013;2(3):99-106. doi: 10.18869/acadpub.johe.2.3.99.

48. Nayha S. Environmental temperature and mortality. Int J Circumpolar Health. 2005;64(5):451-8. doi: 10.3402/ijch.v64i5.18026. [PubMed: 16440607].

49. Mohammadi R, Khodakarim S, Alipour A, Bitaraf E, Soori H. Association between air temperature and acute myocardial infarction hospitalizations in Tehran, Iran: A time-stratified case-crossover. Int J Occup Environ Med. 2017;8(3):143-52. doi: 10.15171/ijoem.2017.1069. [PubMed: 28689211]. [PubMed Central: PMC6679627].

50. Anderko L, Chalupka S, Afzal B. Climate change and health: Is there a role for the health care sector. Washington, USA: Catholic Health Association; 2012. 